January 2017

\title{
Analog Tools in Digital History Classrooms: An Activity-Theory Case Study of Learning Opportunities in Digital Humanities
}

Kalani Craig

Indiana University - Bloomington, craigkl@indiana.edu

Follow this and additional works at: https://digitalcommons.georgiasouthern.edu/ij-sotl

\section{Recommended Citation}

Craig, Kalani (2017) "Analog Tools in Digital History Classrooms: An Activity-Theory Case Study of Learning Opportunities in Digital Humanities," International Journal for the Scholarship of Teaching and Learning: Vol. 11: No. 1, Article 7.

Available at: https://doi.org/10.20429/ijsotl.2017.110107 


\title{
Analog Tools in Digital History Classrooms: An Activity-Theory Case Study of Learning Opportunities in Digital Humanities
}

\begin{abstract}
Digital humanities is often presented as classroom savior, a narrative that competes against the idea that technology virtually guarantees student distraction. However, these arguments are often based on advocacy and anecdote, so we lack systematic research that explores the effect of digital-humanities tools and techniques such as text mining, Geographical Information Systems (GIS) and network analysis have on learning outcomes. This study applies activity theory in a case study of a history classroom in order to understand how introducing digital-history methodology using analog tools like posters and whiteboards can improve student appropriation of history-specific disciplinary skills. The end goal is to provide clear direction for humanities instructors with varied access to technology as they seek to understand how digital humanities tools might still fit within the larger pedagogical practices of higher education classrooms and within the push toward digital methodologies in traditional humanities classrooms.
\end{abstract}

\section{Keywords}

educational technology, activity theory, higher education, authentic disciplinary practices, digital humanities

\section{Creative Commons License} c) (i) $९$

This work is licensed under a Creative Commons Attribution-Noncommercial-No Derivative Works 4.0 License. 


\section{International Journal for the Scholarship of} Teaching and Learning

January 2017

\section{Analog Tools in Digital History Classrooms: An Activity-Theory Case Study of Learning Opportunities in Digital Humanities}

Kalani Craig

Indiana University - Bloomington, craigkl@indiana.edu

\section{Recommended Citation}

Craig, Kalani (2017) "Analog Tools in Digital History Classrooms: An Activity-Theory Case Study of Learning Opportunities in Digital Humanities," International Journal for the Scholarship of Teaching and Learning: Vol. 11: No. 1, Article 7.

Available at: https://doi.org/10.20429/ijsotl.2017.110107 


\title{
Analog Tools in Digital History Classrooms: An Activity-Theory Case Study of Learning Opportunities in Digital Humanities
}

\begin{abstract}
Digital humanities is often presented as classroom savior, a narrative that competes against the idea that technology virtually guarantees student distraction. However, these arguments are often based on advocacy and anecdote, so we lack systematic research that explores the effect of digital-humanities tools and techniques such as text mining, Geographical Information Systems (GIS) and network analysis have on learning outcomes. This study applies activity theory in a case study of a history classroom in order to understand how introducing digital-history methodology using analog tools like posters and whiteboards can improve student appropriation of history-specific disciplinary skills. The end goal is to provide clear direction for humanities instructors with varied access to technology as they seek to understand how digital humanities tools might still fit within the larger pedagogical practices of higher education classrooms and within the push toward digital methodologies in traditional humanities classrooms.
\end{abstract}

\section{Keywords}

educational technology, activity theory, higher education, authentic disciplinary practices, digital humanities 
If=SoTL, Vol. 11 [2017], No. 1, Aft. 7

\title{
Analog Tools in Digital History Classrooms: An Activity-Theory Case Study of Learning Opportunities in Digital Humanities
}

\author{
Kalani Craig \\ Department of History, Indiana University Bloomington, Bloomington, IN 47405, USA
}

(Received 30 March 2016;Accepted 19 August 2016)

\begin{abstract}
Digital humanities is often presented as classroom savior, a narrative that competes against the idea that technology virtually guarantees student distraction. However, these arguments are often based on advocacy and anecdote, so we lack systematic research that explores the effect of digital-humanities tools and techniques such as text mining, Geographical Information Systems (GIS) and network analysis have on learning outcomes. This study applies activity theory in a case study of a history classroom in order to understand how introducing digital-history methodology using analog tools like posters and whiteboards can improve student appropriation of history-specific disciplinary skills. The end goal is to provide clear direction for humanities instructors with varied access to technology as they seek to understand how digital humanities tools might still fit within the larger pedagogical practices of higher education classrooms and within the push toward digital methodologies in traditional humanities classrooms.
\end{abstract}

\section{INTRODUCTION}

"Ban all technology in classrooms!", one article reads (Rockmore, 20I4).Another says, "Students are welcome to shop online during my lectures." (von Schlichten, 2015) Yet another praises the active use of digital environments for supporting collaborative learning and promoting good citizenship (Marcinek, 20l0). Digital humanities as a classroom savior that integrates big-data analysis techniques for text, mapping and social interaction competes against the idea that technology virtually guarantees student distraction on the other. That division results in discussions of digital-humanities pedagogy classroom praxis that are largely anecdotal or advocacy-oriented.

The focus on advocacy has considerable value. Anecdotal stories suggest that student engagement improves when students encounter humanities challenges mediated by digital methodologies like GIS or other big data techniques like text mining and network theory (Dougherty \& Nawrotzki, 20 I3; Kelly, 2013). However, these anecdotal results are generally produced in classrooms run by instructors with advanced skills in the technology they are teaching and in classrooms well-equipped for technology-based inquiry. Such settings are rare and difficult to duplicate, and many instructional technologies go unadopted because instructors lack the resources or motivation to make major changes to their teaching practice (Blin \& Munro, 2008). As a consequence, it's difficult to imagine, much less study and produce quantitatively significant learning outcomes for, a digital-humanities-based activity that can be widely distributed to campuses with varying institutional support for classroom technology.

\section{Activity Theory}

One approach to bridge the gap between systematic activity design and systematic learning-outcome study for the digital humanities is activity theory. Activity theory situates learning in a sociocultural environment, and particularly in the shared collective exercises that are at the core of digital-humanities pedagogy (Engeström, 1987; Greeno, 2006; Vygotsky, 1978). The fluidity of group organization, technology interface, and classroom resources makes it difficult to assess the role technology, or indeed any one variable, has in any learning outcome (Danish, 2013). Activity theory helps untangle individual components (the learning objective itself, classroom norms, lesson-plan rules, the division of labor, the participants), situate these components in their socially constructed context, and make it easier to individually examine the role of any tools that mediate participants' engagement with the other classroom variables.

This study applies activity theory to the design of a series of activities in a history classroom in order to explore how introducing digital-history methodology, which generally narrow the use of GIS, big-data text-mining techniques and social-network analysis to research on historical perspective and context (Seefeldt, D., and Thomas, 2009), might change student learning outcomes. In the examples that follow, activity theory is used to systematically trace the effects of decisions about the length, scope, and structure of a digital-humanities activity on students in a 25 -person undergraduate introductory history course. The 200-level course contained a writing intensive component and drew from the student body of a large Midwestern university. Students were age 18-25, representing 14 different majors (including undeclared students) from all undergraduate levels. The current study also acts as a roadmap for a larger quantitative study that will examine some of the changes that new mediating artifacts and rules might have on the community and division of labor in a larger lecture classroom.

Applying activity theory to an undergraduate humanities classroom makes several contributions to both educational research and humanities pedagogical practices. Although some work has been done on the value of using activity theory to structure writing and composition courses and on the overlap between composition and entry-level survey history courses (Adler-Kassner, Majewski, \& Koshnick, 2012; Russell, 1997, 2013), activity theory is rarely applied to humanities pedagogy broadly or history pedagogy on a narrower basis.A demonstration of its value in humanities classroom-activity planning broadens the reach of this valuable theoretical approach to SoTL audiences in humanities at large. More importantly, activity theory provides a systematic approach to evaluating the learning outcomes that are supported by modern data analytics techniques, a perspective that expands the use of technology in history learning beyond simulations and games (Morgan, 2013; Robison, 2013) and counters media narratives that mitigate the wide media swing between technology as a classroom 
evil and technology as an unlimited catalyst for positive change (Cuban, 1986; Nardi \& O'Day, 1999).

The most common way activity theorists make classroom in a classroom using an activity triangle (Roth, 2004). It does so by in a classroom using an activity triangle (Roth, 2004). It does so by makperience more visible in service of making good pedagogical choices. To that end, I will first use activity theory to break a generic historical-thinking activity into the individual features that combine to shape the activity: classroom environment, the activity's content and the available tools. I will then apply that general process more specifically to three single-session activities using three different digital-history methodologies in service of a discussion of the value of single-session activities and analog tools in general. By examining three different methodologies together, we can see how the rules, object, and division of labor vary or overlap for a specific instructional goal. The three activities together also demonstrate
the broader value digital methodology offers as instructors bridge the broader value digital methodology offers as instructors bridge
the gap between their expertise as historians and the barriers the gap between their expertise as hrten face as they tackle the practice of historical thinking

The simplest version of an activity triangle represents the subjects in the classroom-students-along with the objective of students' activity and the tools they use to mediate the lesson
they are learning [Figure I]. Figure I also includes the object and mediating artifacts a professional historian might have for historical-inquiry activity, which helps clarify the changes we might make elsewhere.

Figure I

STUDENTS' MEDIATING ARTIFACTS
(TOOIS):

SToots):
(Toutbook
- eecture

- Lecture

HISTORIAN'S MEDIATING ARTIFACTS
- Contextualized historical

SUBJECT:

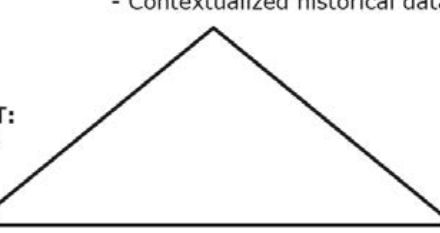

STUDENTS' OBJECT:
Find historical fact(5) using
memorized names/dates/-
places HISTORIAN'S OBJECT:
Use contextualized historical
deting

from Engestrom, 1987; Danish, 2011

Activity theory helps us isolate the physical, psychological and cultural artifacts that mediate one's actions. In this case, the mediating artifacts for students are classroom tools (textbook, lecture), while the mediating ars are cor prossional historians are comprised of disciplinary knowledge that has been appropriated elements of this tacit disciplinary knowledge the practice of taking persective, for instance have previously been placed infor "decoding the disciplines" frameworks to identify the bottlenecks "decoding the disciplines" frameworks to identify the bottlenecks
that prevent students from practicing history the same way a professional historian might (Middendorf, Díaz, Pace, \& Shopkow, professional historian mign
2007; Wineburg, 2001).

Activity theory then highlights the kinds of decoding practices and perspectives identified by the "decoding the disciplines"
framework, showing us where and how we might systematically

s:ikdoi.org/10.20429/iisotl.2017.110107 transform a physical mediating artifact present in the classroom-a primary source as a collection of pages to read-into an appropriated conceptual tool-a primary source as somethin to make sense of and use in an argument (Engeström, 1991). Arranging the classroom infrastructure more systematically help us see how the appropriation of and use of these more conceptual tools by students can help them engage more meaningfully with the orical tasks in which we want them to engage.

Specifically, novice historians often focus on the memorization facts as their learning objective, while professional historian view the creation of a historical argument as their primary objective (Grim, Pace, \& Shopkow, 2004). In more specific terms,

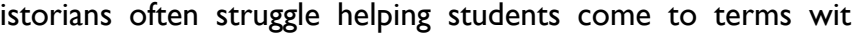
(Wix of familiar and unfamiliar in historical primary sources (Wineburg, 2001). The acknowledgement of this disconnect makes tho apparent that students see their goal as drawing facts from pieces of evid have been assigned, while historians see individual peces of evidence from the texts as the mediating tool that helps I 0 isolate each of the classroom features in order to better see how they interact.

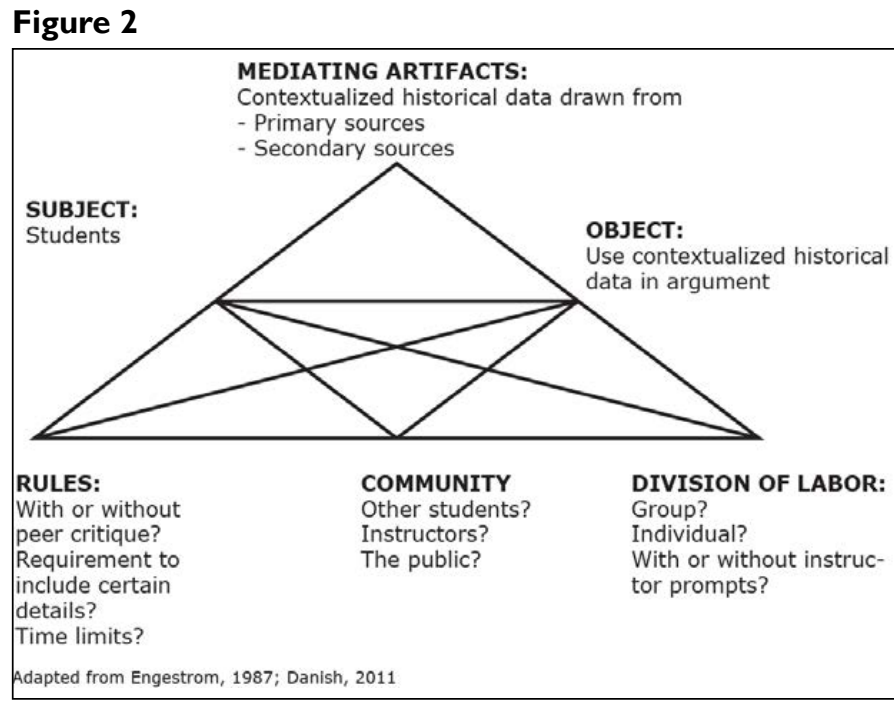

For instance, if not all students have laptops, at least one of the mediating artifacts must replace the computer and its allowance for writing, drawing and displaying. Similarly, if a class has been divided and will change the efficacy of the mediating artifacts depending on rules of the activity are organized.

Exill familiar environments breaking a familiar environment into smaller, less familiar pieces, and breaking an unfamiliar environment into smaller, more approachable pieces (Wineburg, 2001).A traditional history classroom might set out specific rules about how a student encounters a primary source: close reading outside of class coupled with the Socratic method during a lecture (Pace, 2004). Collaborative learning environments in history classrooms change the rules, community and division of labor in a history classroom in order to better affect and track individual learning outcomes (Pace, 2004), but the underlying mediating artifact is still a combination of close-reading and Socratic questioning methods. Additionally, it's difficult to assess individual student learning outcomes when
student appropriation of these disciplinary skills are tested via summative assessments in the form of broadly writ essay exams and long research papers that require many steps and many skills (Shopkow, Díaz, Middendorf, \& Pace, 2012).

Adding digital-history methodology as a mediating-artifact layer on top of a primary-source mediating-artifact layer changes the classroom in one very important way: digital methodology often requires smaller, predictable chunks of primary source. These smaller pieces then require rules that change how students approach the primary source in equally predictable ways. Students who are mining a text for word-cloud purposes have more directed rules for reading than students who are reading a text with the broader, more general purpose of reading "for context." Instructors who
give out those new, more direct rules, can guide students toward give out those new, more direct rules, can guide students toward
the specific things that make up context- themes, places, events, people, frequency of occurrence - and in doing so, shift the object of students' engagement to more closely parallel the instructor's object. In otherwords, these smaller predictable chunks provid without leaving them adrift and confused (Yorke, 2003). This same balance between student autonomy and structure means formative assessments using these tools are likely to make studen learing outcomes more visible for instructors (Sadler, 1998).

By using digital tools to explicitly redirect students' object of activity, the instructor can then begin to help students develop the psychological tools that underpin the disciplinary practices common to a professional historian (e.g. understanding historical context).As the physical tool helps students shift their perspective, they begin to reflect on the purpose of taking historical perspective as it supports a historical argument. The appropriation not just of the digital tool but also of the instructor's objective for their ow restructures the students' own understanding of their approach to the practice of history. While this appropriation may not always lead to a metacognitive awareness of what it means to practice history, it may begin to develop that metacognitive aw

The three digital methodologies I explore below-spatia history, text analysis and network analysis-accomplish this restructuring of knowledge differently. The mapping exercises embedded in GIS and spatial history activities embedding the bits and pieces of an unfamiliar geography of a far-off past in the larger context of a tool students regularly use to get driving or level family with a text by breaking a text into smu familiar pieces. Finally networks take hard-to-analyze, difficult-toremer seemingly haphard collections of people and clusters them into smaller, more approachable sets of relationships.

\section{Mapping}

While students generally know where Europe is-and they associate the medieval period with European centers like London or Paris - they are often unfamiliar with the basic geography of the
medieval Mediterranean as a whole. That lack of familiarity limits students' understanding of geography's role as a historical actor, as it shapes how people interacted with and moved through their nvironment. It also gives us a starting point for how to design this

sample lesson in the activity triangle.
The instructor's primary goal was one of historical perspective taking: students should be able to understand how the agency of historical actors is affected by geographic context. Specifically, the case study uses Ibn Shaddad's Rare and Excellent History (Ibn-Shaddad, 2002), a Third-Crusade biography of Saladin, to demonstrate how desert geography and slower travel times limit historical events nunfamiliar ways. We also want to highlight the emotions people assign to geographic space as they write history. The object of perspective-taking on the right side of the activity theory triangle 政 the and

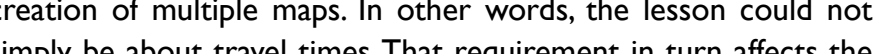
Thision be abu travel times. That requirement in turn affects the create individ, requiring students to work in smaller groups to exercise was in haps. The other constraing element for this aptops. Tha further emphasized the small-group division of had but it also constrined output tools for each of those (onser in-class limitations also shaped the advance-reading directive. The activity requires multiple maps, which in turn requires different information about the geospatial environment Ibn Shaddad describes. Student groups were therefore asked to identify basic themes, historical figures and emotional highlights of the biography in addition to place names and movement in order to tie geospatial formation to other content in the text.

Figure 3

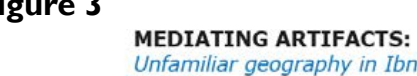

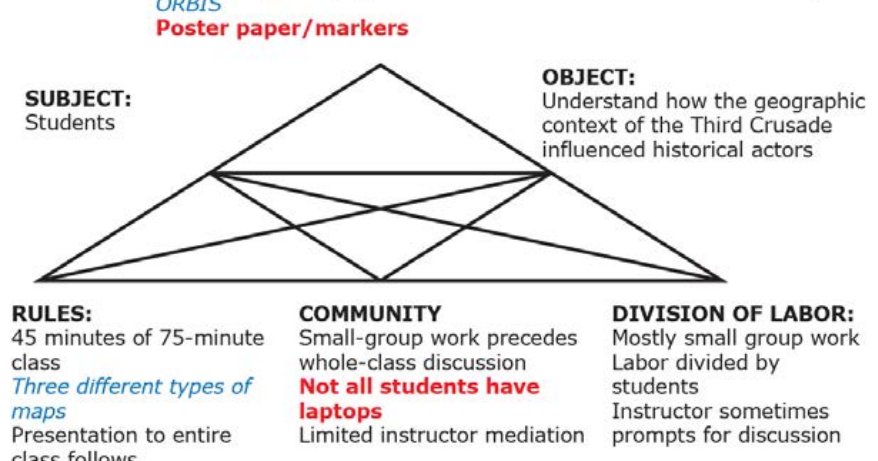

The more practical details of the lesson plan are shaped by the arger limiting factors that hew toward laptop access and learninggroups -4 groups of 4-6 people in a 20-25 person classroom-to create one of three maps. We then discussed their map in context of the other student-group creations. One GIS map focused on travel times using medieval travel methods would be accompanied by two cartograms, in which visualizations of geographic space of mention. The three maps made heavy use of the students 
assumption that their learning objective is to memorize names, dates and places, but the goal for each map shifted memorization to the tool category in order to serve my learning objective: an argumentation exercise that communicated geographic significance based on the focus of their cartogram. Additionally, the integration of the three representations into a single classroom activity addresses the digital-literacy issue of maps as malleable objects static representations of "true space." Finally, the lesson allowed students to make use of digital tools like Google Maps, Stanford ORBIS (which provides travel-time calculations using ancient trave methods), and Wikipedia on their smartphones, while asking for an explicitly analog output: a poster-paper sized hand-drawn map.

\section{Lesson Plan}

Introducing students to cartograms as a branch of GIS and mapmaking required particular attention to the idea of maps as malleable argumentative representations. That meant a short introduction using 2012 Presidential Election electoral maps to demonstrate spectrum of cartogram alternatives to GIS maps (Gastner, Shalizi a Newnan, 2005, New an, 2012) US ants were first shown a


red and states sending electorat vors to the Democrat candide in bye [Figure 4, where red is light gray and ble is dak gra]. They were then shown an electoral cartogram in which the Tepresentation of geographic size was mitigated by population density [Figure 5]. The final cartogram used the same populationdensity alteration of geographic space, but instead of red/blue only, the map represented a spectrum of percentage Democrat Republican split, represented by shades ranging from red to purple to blue [Figure 6 , and here the subtle gray shades demonstrate how well distributed the popular vote was geographically between the two candidates].

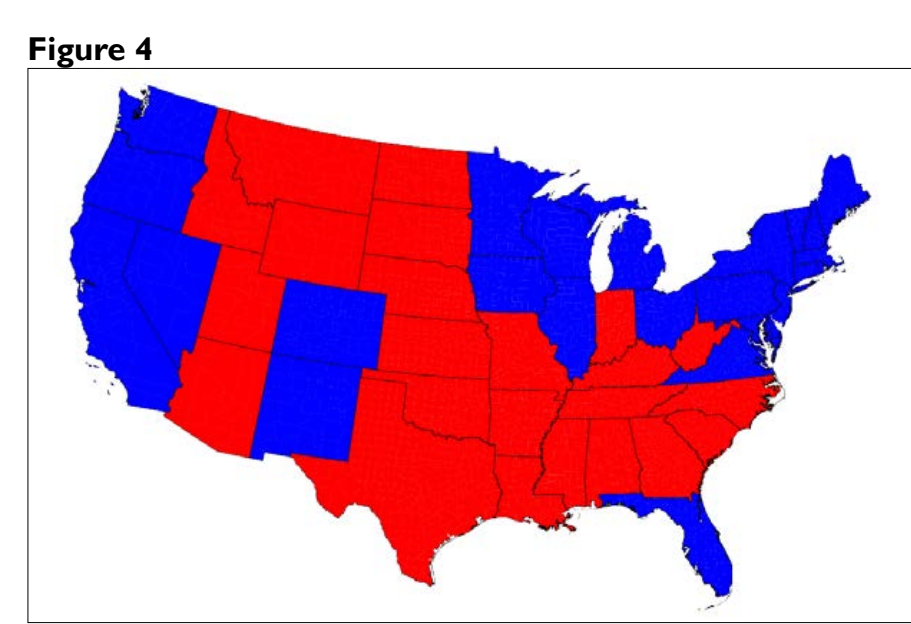

As we moved through each map, students were asked to describe that map's argument about the political distance between Republican and Democrat and the percentage of the country that subscribed to Republican or Democrat value systems. We used their responses-which moved from Republican-dominated and
widely politically divided to mixed and more politically centrist as they viewed each successive map-to frame the idea of maps as
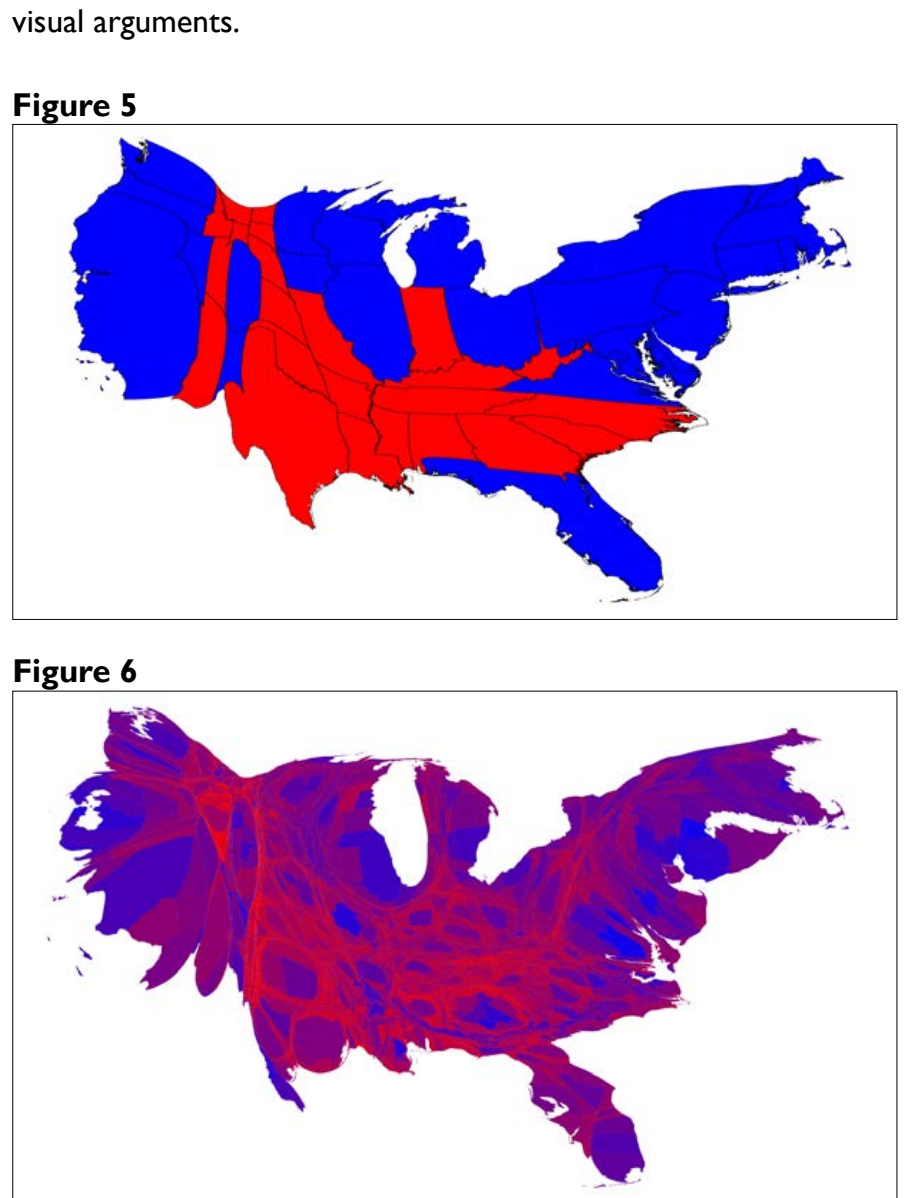

Figures 4-6 ๑) 2012 M. E.J. Newman

Student groups were then asked to use the basic visua principles in the electoral cartograms-color as a representation of difference, size as a representation of importance, and distance as a representative of both geographic distance and conceptual distance-to create an argumentative map of their own. The instructor prompt focused on a particular kind of historical perspective-takng for each type of mapping exercises, providing as they thought about what their argument would be [Figure 7].

\section{Outcome}

The primary shift each student group made in both small-group map construction and in whole-class discussion was to reduce their percepton of Jerusalen's importance in lbn Shaddad's in pive. That small shin in geographic emphasis is a major shift in my activity triange during the lesson desing in his mirative, lbn Shaddad focuses on Acre, but students often ignore his focus even in close reading or Socratic-method discussion. Their very modern perspective of the Middle East centers on conflict over holy sites in Jerusalem. By giving students the tools to explicitly rebuild Ibn Shaddad's narrative, their perspective shifts to a twelfthcentury view of the Middle East, a perspective they can then use to understand Ibn Shaddad's very different geo-political context. In whole-class discussion, two students, one from the frequency cartogram group [Figure 9] and one from the experience
Figure 7

\begin{tabular}{|c|c|}
\hline $\begin{array}{l}\text { A Travel Map } \\
\text { How does landscape alter } \\
\text { people's experienceses } \\
\text { How long did it take to get from } \\
\text { place to place? } \\
\text { What routes did people take } \\
\text { from place to place? }\end{array}$ & \begin{tabular}{|l} 
A Frequency Map \\
- Which locations are more \\
important from Ibn Shaddad's \\
- Woint of view? \\
Where did Saladin spend most \\
of his time? \\
How is the frequency landscape \\
different from the population \\
landscape?
\end{tabular} \\
\hline $\begin{array}{l}\text { An Experience Map } \\
\text { Where are Saladin and Ibn } \\
\text { Shadda's sositive experiences? } \\
\text { Negative? } \\
\text { How did Ibn Shaddad feel about } \\
\text { the different places he'd been? } \\
\text { How did he portray Saladin's } \\
\text { experiences? }\end{array}$ & \\
\hline
\end{tabular}

to the geography in Rare and Excellent History. Prior to reading the text, they assumed that Jerusalem would figure heavily in the Third Crusade. As they were reading the text, the students said, they began it still held a place of honor. Given covera of the lsralipalestinin conflict, this is hardly surprising since students tend to import familiar knowledge into their historical understanding of events taking place in geographies with which they have little personal experience.

After the mapping exercise, however, both students described their surprise that Jerusalem was far less dominant than Acre a tiny fortress on the Mediterranean coast, which figured far more heavily in Ibn Shaddad's narrative than their unstructured reading and notes suggested.At this point, a student from the GIS/travel map [Figure 8] added support for this shift away from Jerusalem by pointing out that Acre was the only city connected to two separate travel routes that figured highly in Ibn Shaddad's narrative.

From a digital-literacy perspective, seeing the distorted, but stil recognizable, geographic space of the Middle East helped students to understand the tension between a static "truthful" set of driving directions and the constantly shifting geographic space that is the historical past. Mapping distortion is possible with GIS technology, but displaying distorted mapping layers with geographically accurate mapping layers on a single screen would be nearly impossible in a standard classroom with one screen at the front of a classroom. Using poster paper actually extended the GIS technology on which students were basing their maps in productive ways. The distortion coupled wh simulaneous display fostered very fruitful discussion lignmenth

Additionally, the individual discussion and initial shifts in response to the actuat information in the primary source as conpad student assumptions about what would be in the primary source based on their knowledge of the modern Middle East-were fostered by each individual mapping exercise but only firmly cemented by whole-class discussion of all of the maps together. The initial division of tasks suggested by an activity theoretical breakdown of the classroom emphasized the value of a wrap-up comparison, and the affordances of the analog tools that also came out of an activity theory analysis made that comparative discussion more productive. One of the major advantages of digital methodology performed with nalog tools is its escape of the limitation of a single classroom screen display-This exercise allowed students to simultaneously see all of the map-making products, and it supported two groups' choice to distort the geography of the Middle East in order to make an argumentative point.

Figure 8

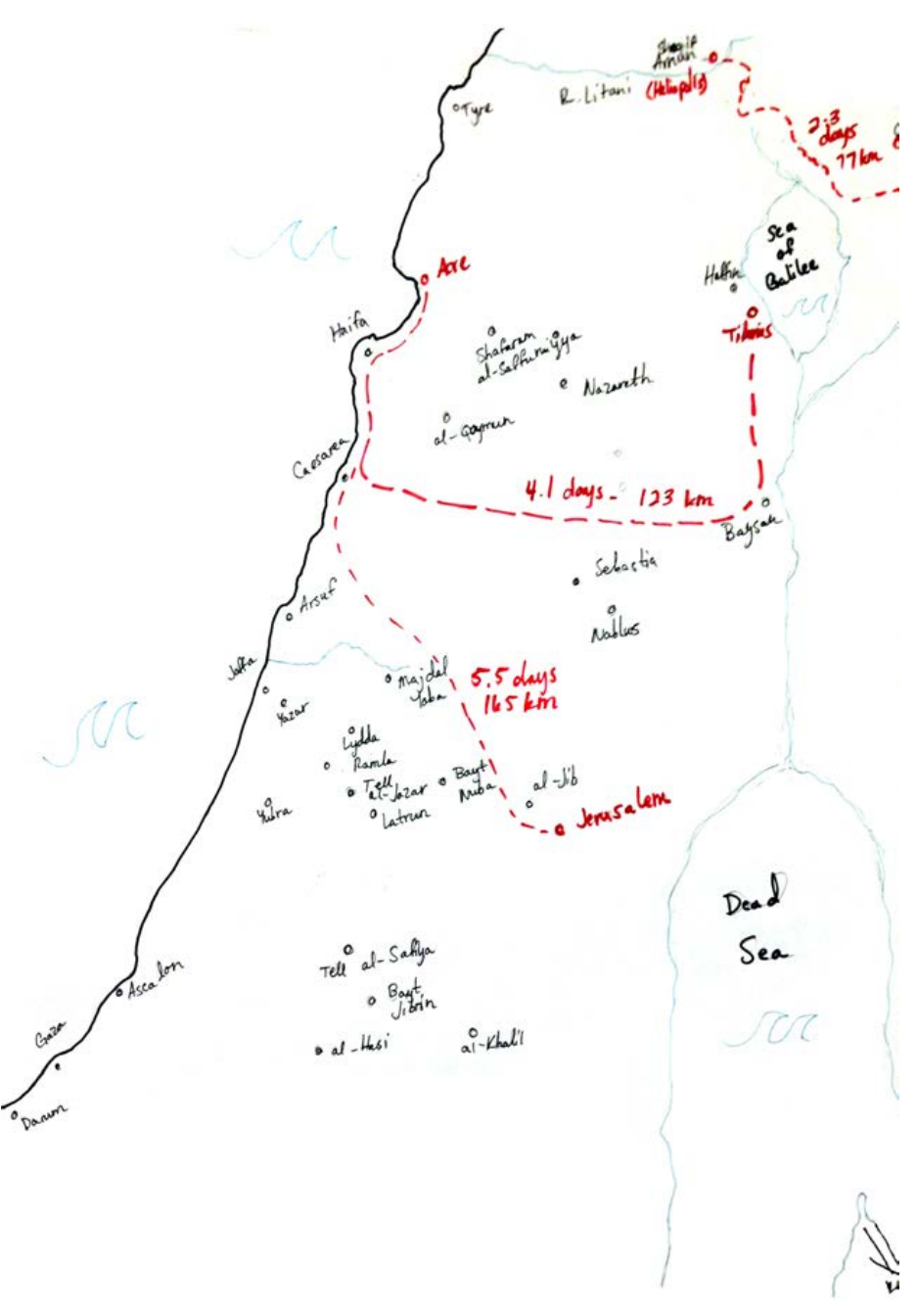

Text Mining

As with the mapping exercise, this text mining exercise focused An aligning student objectives about memorization with instructor

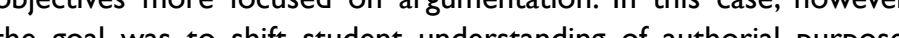
Synthesizing to shif student understanding of authorial purpose. corroborative purposes or to understand ongoing them signifan historical-thinking skill set, particularly in a very hre text like the lliad, the subject of this example. Breaking large confusing unfamiliar narratives into very small, familiar, easy-to-digest pieces and then reassembling them can help students find thematic and corroborative structure in ways that instructors struggle to do with open-ended discussion alone. The exercise focused on chapters 6, 7, and 8 of the lliad, in which (respectively), Homer explores Hector's familial connections, the role of honor and the gods in war, and the Homer's lis an instructor, my goal was to help students understand 
emotionally so they had a stake in his battle with Achilles and then his death, but also to understand the historical artifact of the text's emphasis

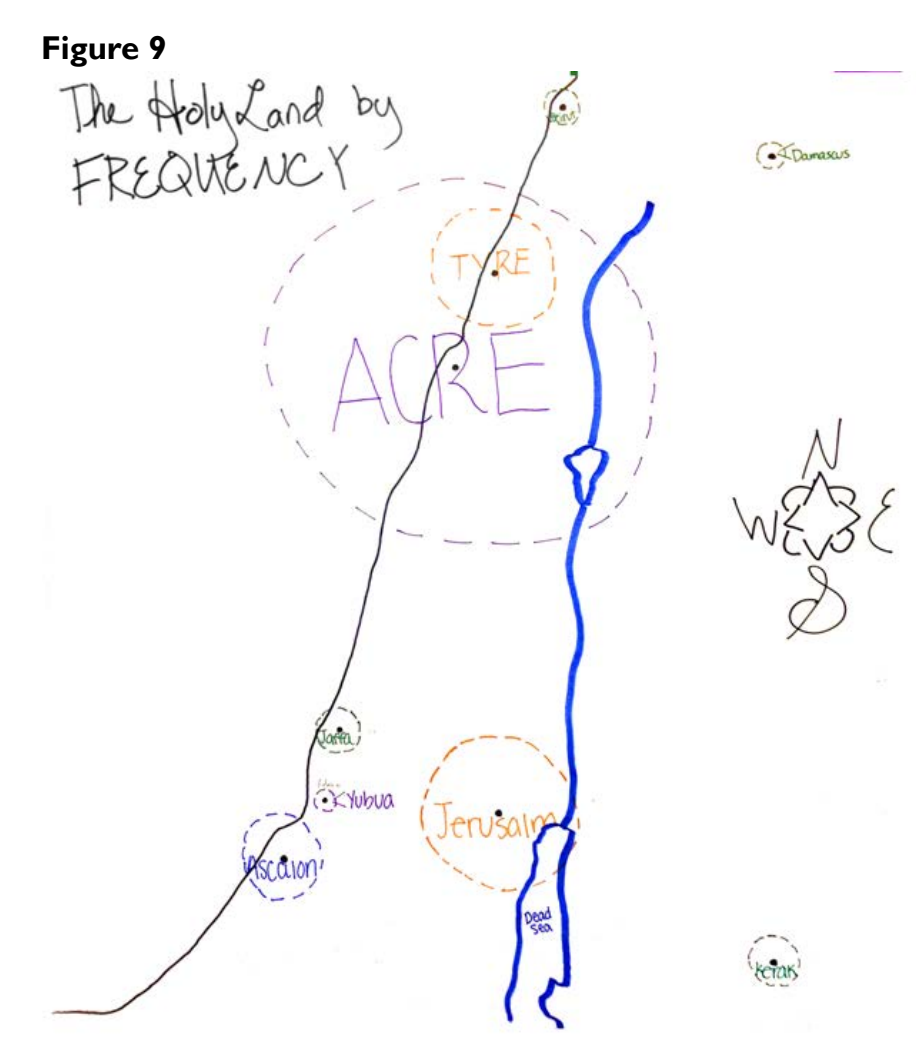

Figure 10

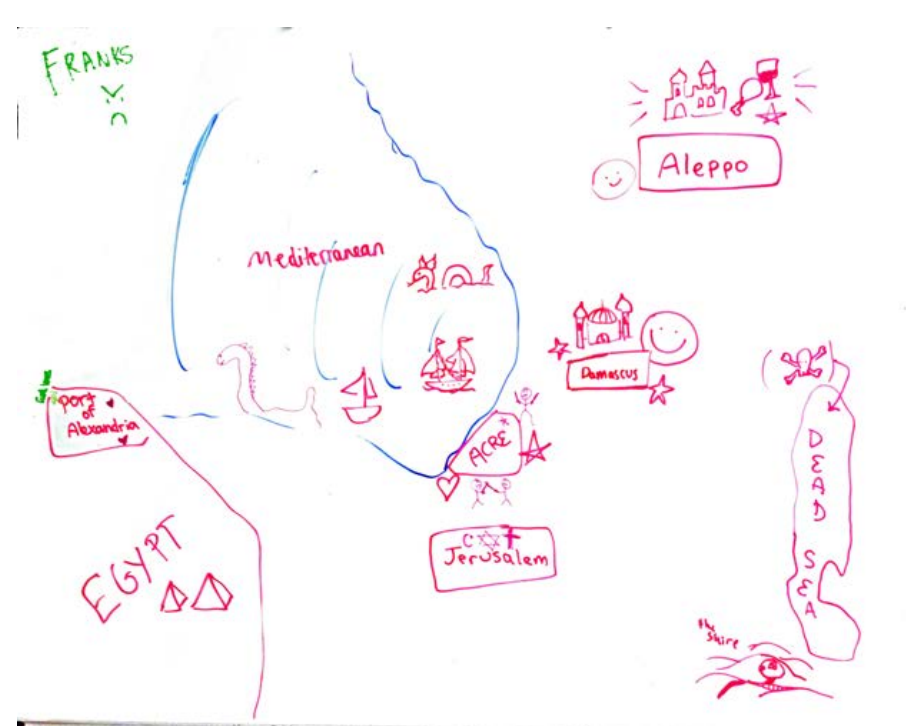

hattps://doioi.org/10.20429/iisotl.2017.110107
I introduced the activity by suggesting that an author has very specific goals for communicating to an audience when they structure narrative. With authorial purpose as our object on the right side of the activity theory triangle [Figure $\mathrm{II}$ ], and a rule that requires the activity triangle focuses on how to organize students to see authorial purpose as it changes across different chunks of the text. Word clouds provide a simple, but effective, approach to the kind of analytical partitioning that text mining encourages. Activity theory analysis coupled with previous experience with the mapping exercise again suggested that the most learning gains would come from combined whole-class discussion after diverse small-group tasks. It can be difficult to produce even a simple text-mining artifact like a word cloud with limited experience, so students in three smaller groups were given specific instructions about how to identily characters an themes of interest in their section of the reading - one chapter of the lliad-and then track those themes. As with the mapping exercise, no all students had laptops, so artifiacts needed to be analog (in this cas white boards instead of poster paper, although poster paper worls

Figure II

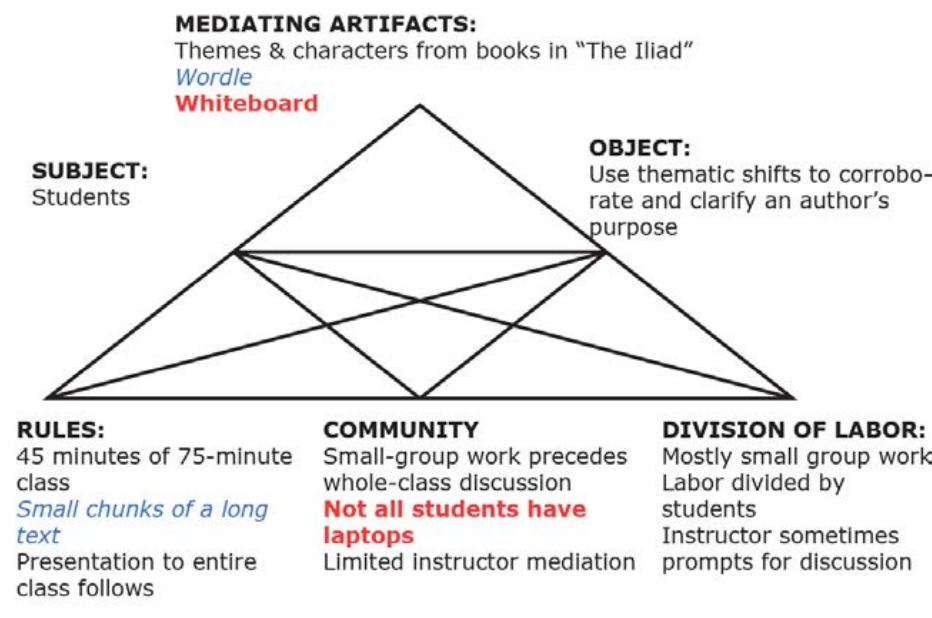

dapted from Engestrom, 1987; Danish, 201

\section{Lesson Plan}

Students were introduced to Wordle (a web-based word-cloud generator) with the text of the first chapter of the lliad so they had an example of what their text-mining word cloud should look like. We also used that Wordle cloud to discuss the importance of size, color and distance as elements of argumentation. Each of these elements emphasize values drerenty in visual argumentation, so this digita literacy to bear in the production section of the exarcise. nlike the maping exercise, the backround on word clouds was therwise minimal since each student group had a laptop and the grous could experiment with their thematic and a lareer weighing easily to best $\mathrm{ft}$ their argument about what was important in the chapter.

In the exercise itself, students in each group negotiated the themes and characters they had tracked individually manually assigned frequency values to each of the characters and themes the group deemed important and then used one computer to enter those values and themes into Wordle, assigning manual weights using Wordle's advanced settings (http://www.wordle.net/advanced).
Students were then ask to produce a word cloud on the white board arguing for their ranking of thematic and character importance, using Wordle and their understanding of the simple argumentative strategies introduced at the beginning of class to guide their color, size and placement choice. As with the spatial-history exercise, the whiteboard acted as a mediating tool and was divided into three word clouds for chapters 6,7 , and 8 of the lliad, in that order.

\section{Outcome}

The first shift in perspective was visible when students began to negotiate thematic frequency. In the process of a seemingly quantitative discussion about thematic frequency, students began to make qualitative judgements about the generic themes they had tracked on an individual basis (family", "battle", "war"). These themes narrowed very quickly as a consequence of discussion, replaced by themes rooted in authorial language like "guest-friendship" or "tides of battle" begin to emerge. This process indicated an advantage to small-group work, which promoted a more complex understanding of and deeper engagement with the author's purpose. Students then required each student to re-engage with and partially re-read the text. which as a practical matter is a victory of its own.

When the groups finished their word clouds, each group then presented a short 2 sentence overview of their word cloud to ther peers in a groups. The students presenting book 6 focused their verbal description on the very mundane day-to-day interphy between warrior culture and family culture, and the role the gods had in encouraging or discouraging the balance between those two poles [Figure 12].

Figure 12

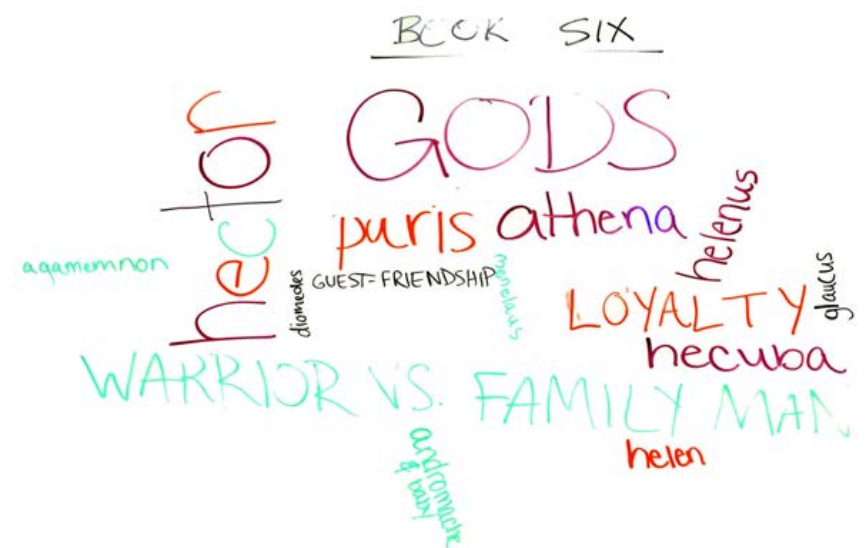

The students focused on book 7 highlighted a similarly human struggle: the tension between life and death [Figure 13]. They noted that in comparison with chapter 6, that focus was less on day-to-day of the metaphysical afterlife. As with the strugate between warrio culture and familial loyalty however, the gods played a role in bartior (or unbalancing) that tension.

Finally, the students working through book 8 highlighted the very high-level conceptual struggle that exists when we see hierarchies of power clashing [Figure 14]. Fate and its inscrutable invisible hand overwhelmed even the gods in book 8 .
In the whole-class discussion that followed, students working on book 6 noted an initial reaction of surprise as the themes emerged for books 7 and 8. They were dismayed that the close-knit family Homer presents in visions of Hector playing with his young son is destroyed in book 7 and devalued in book 8. Students working on book 7 picked up on the implicit emotional attachment book 6 develops between the reader and Hector, and suggested that the destruction we see in books 7 and 8 would seem unimportant and distant wh hout the connection to the worldy values of war and family in book 6 . Finally, the students in group 8 noted that even the

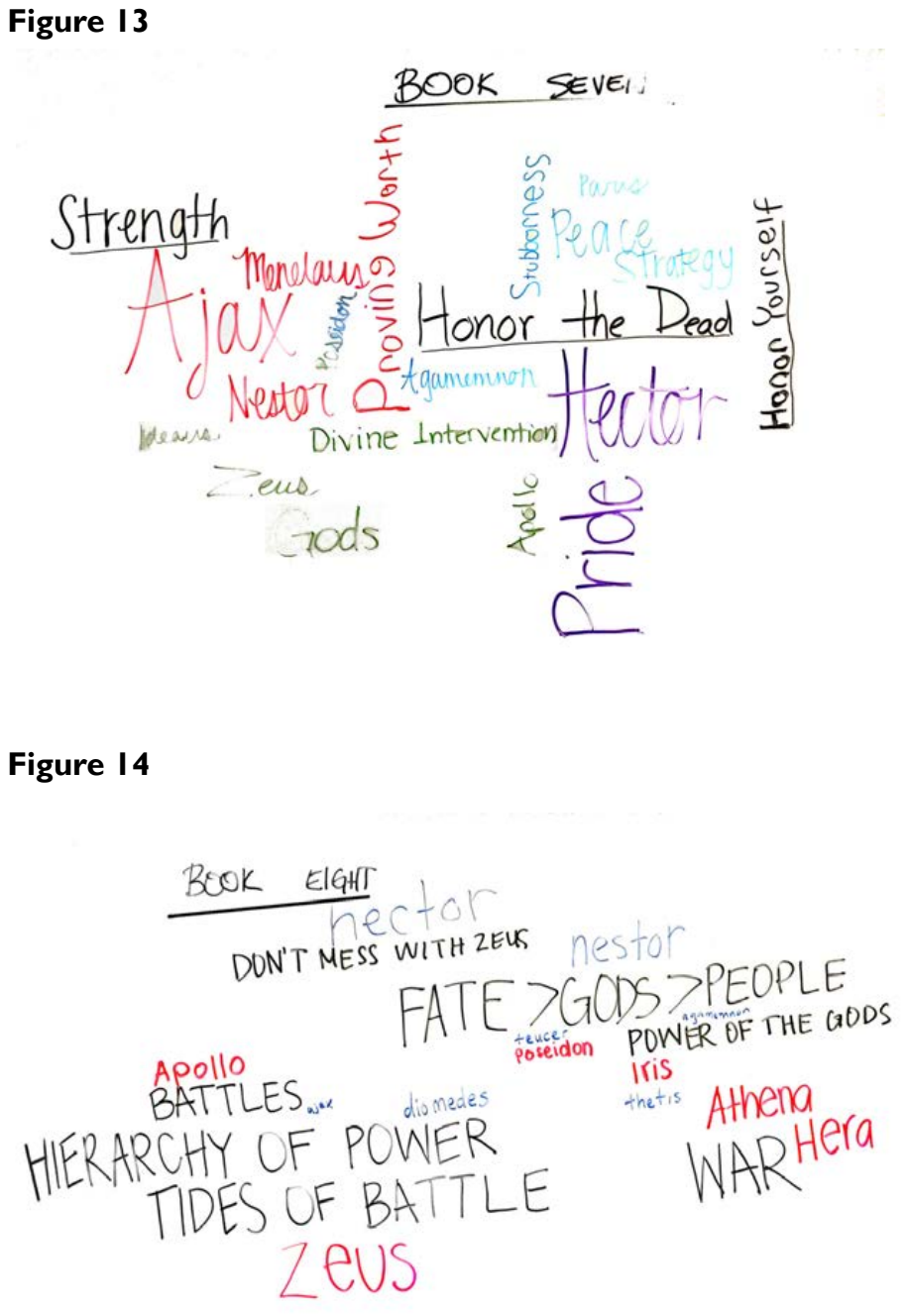

Zeus unable to save way of creating a parlet between the human nature of the gods Whe shortived relationships that humans create One sident in group 6 then arged that the tie between Homer and his son and Zeus and his son is as much about a noble lineage ending as it is about emotional attachment, despite the fact that Zeus displays far less personal affinity for Sarpedon.

This student's tie between social status and family ties marked a shift in the discussion from narrative to historical evidence. As with the mapping exercise, students made the biggest conceptual leap after engaging first in a very deep encounter with a smaller subset 
of information and then comparing and discussing their conclusions they need to craft an argument. In this case, our goal was to help in the context of the other groups' artifacts. In this case, students focused on the shift from human agency in chapter 6 to divine
agency in chapter 7 and finally to the overwhelming sense of fate that agency in chapter 7 and finally to the overwhelming sense of fate that
reduced both sets of agents to pawns in chapter 8 . Their conclusion was that Greek audiences idealized close family relationships as much for their emotional attachment as for their indication that familial lineage is important for inheritance and social stability, but that the emotional connections created by familial relationships aren't subject to destruction by fate in the same way as social stability. This shift toward integrating an audiences' social and cultural norms about class and familial organization, audience reception of the lliad and Homer's authorial purpose is very much in line with a professional historian's analysis of audience makeup as part of understanding authorial purpose. It is also very hard to accomplish in a single class session, and
the adoption of text mining to break authorial structures into smaller the adoption of text mining to break authorial structures into smalle pieces and then display those pieces visually contrib
ability to engage with this particular historical task.

To demonstrate both the value of, and the pitfalls of, this approach
to to text mining, we wrapped up class with an example of what each book would look like if it had been modeled by a computer rather than by a group of humans. Book 6 is shown below [Figure 15] an examplo.

In this discussion, students immediately highlighted the more granular nature of the computer generated word cloud. For instance,
"son" and "wife" are separate rather than combined into "family". Students also pointed out the value of an algorithmic presentation, though. "Noble" and "lineage," the underlying concepts that tie family values to guest-friendship in the student-generated word-cloud for book 6 , are far more visible in the computer generated word cloud than in the human-generated word cloud.

\section{Figure 15}

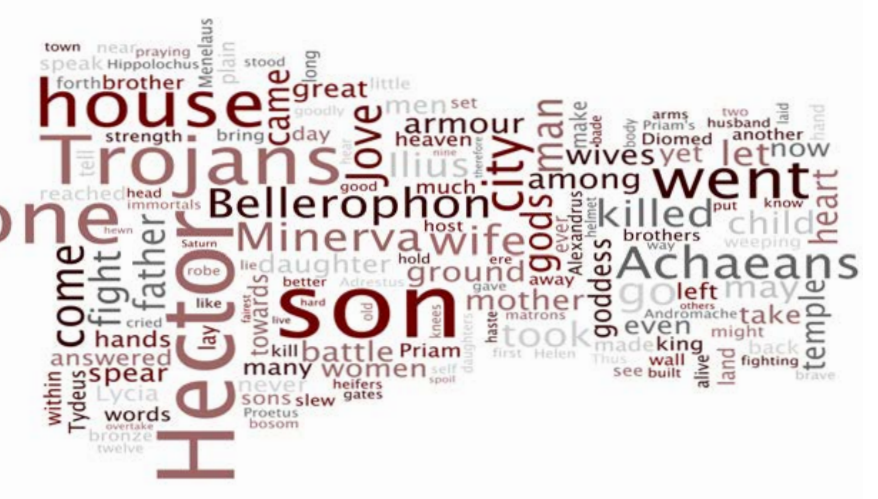

From a digital-literacy perspective, seeing their own topic word cloud juxtaposed with the computer-generated version helped and where their analysis had gaps. This opened the door for a conversation on the ways in which natural-language processing and customization act as a filter, for good or bad, when we use Google repeatedly to search for information about the world around us.

\section{Network Analysis}

Understanding context-social norms, cultural values, historical events-provides students in history courses with the informatio n the fictional description of a set of social ties as containing interaction, social of historical norms related to interperson focus also provides a digital-literacy lesson in social networks and their role in shaping contemporary relationships.

The background of this lesson comes from an existing scholarly exploration of social networks in epic poetry. Pádraig Mac Carro Ralph Kenna examined the networks in The lliad, Beowulf and the son Wiar Were basilial and social networks that actually extsed (Mac Carton \& Kenna, 2012). The authors in this network theory plece descibed thee kinds of behavior that create the features of a ("nodes" ("nodes" or circles in Figure 17) to have close ties ("edges" or lines between nodes) to ocher people with similar backgrounds, likes and dislikes (a pattern visible in the highly clustered nature of Figure I7) balanced behavor, or the indency to engage not in exclusive two-way arge clusters of dissimilar people are easily disrupted by the removal of on or two nodes (illustrated in Figure 19 by the fact that well connected nodes at the center of a cluster connect to ther wellconnected nodes at the center of other clusters and removing these. few well connected nodes would dramatically reshape the network). Activity theory analysis coupled with previous experience with both mapping and text mining again suggested that the most learning gains would result when students pursued a local object of activity at the group level and were then able to explore and contrast that local object in the context of a larger whole-class framework. While it was valuable for students to see patterns within their group, the whole class discussion helped them to see how persistent and robust their own patterns were. With the context provided by historical social norms as our object on the right side of the activity theory triangle [Figure 16], and the three types of interactions laid ou group focus, the remainder of the activity triangle focuses on how to help students reflect their understanding of each network feature as a way of reconstructing their historical understand of the tex. mining exercise, which preceded this class session, as a foundation for creating the relationship patterns that grounded their network They were instructed to think about whether their network did or did not meet the specific requirements of their assigned network using space, distance and color as with the text mining exercise. To ive can be visualized, they searched for "network analysis" at Googte Images (https://ww the central classroom computer and visualized their own Fasebol network using YASIV (http://www.yasiv.com/facebook, now defunct). These minimal computer interactions, which generally impose some These minimal computer interactions, which generally impose some
color on the visual organization of a network diagram, also mean some requirements for the mediating artifacts: white boards work but chalkboards do not, because of the color requirement, so in rooms equipped only with chalkboards, poster paper works best.

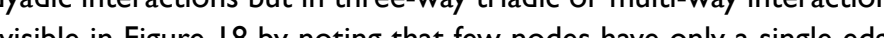
(Viste in figure 8 by noting that few hodes have only a single edge by Mac Carron and Kenna providing an easy way to divide smallStudents used their experience of character frequency in the text-

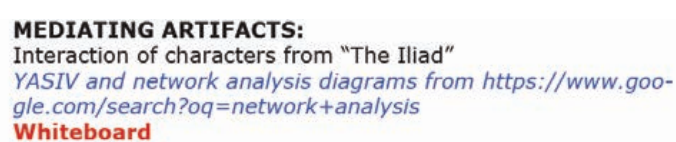

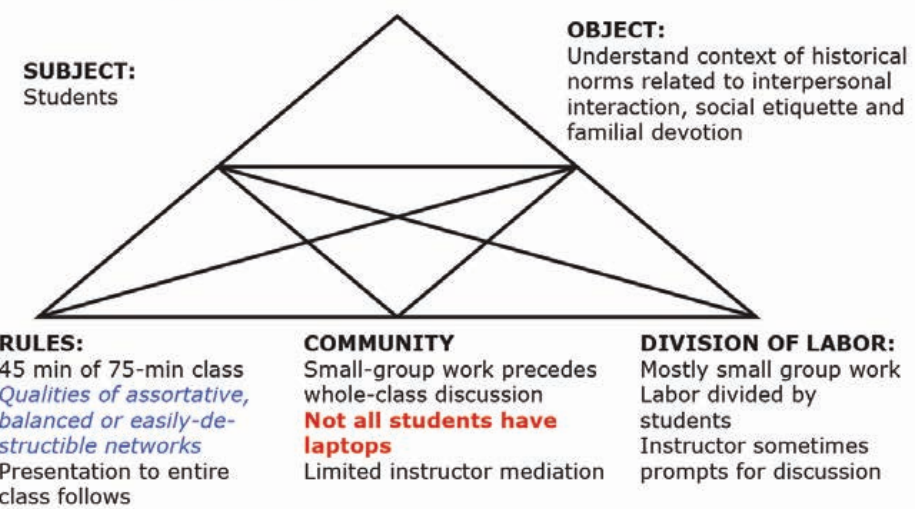
estrom, 1987; Danish, 2011

Lesson Plan

Each group was instructed to examine one aspect of a social network Student assigned to study the assortative nature of the network focused on the appearance of tightly clustered sub-networks; students whe wered at the destructibility of a network focused on the appearance highly-connected nodes in an individual subnetwork acting as edges to highly-connected nodes in other sub-networks. Rather than simply representing the lliad's network using their assigned feature, howeve students were asked first to discuss whether they thought the lliad's network met the qualifications of their assigned feature.

Their goal was to represent the results of their discussion as an argument in visual form. To support that, we again discussed basic principles of good data visualization: spacing to represen conceptual distance, color to represent categorical grouping, and size to represent frequency or some other consistent measure of importance. Students were given several examples of networks that were good representations of their assigned feature, and as discussion continued and individual groups began to ask questions about how they might make their argument clear, I provided specific examples. For instance, the balanced-network group asked, after looking at the relationships they documented in the lliad, how they might present a dyadic, or unbalanced, rather than triadic, or balanced relationship. I suggested putting nodes with many connections in a small cluster at the center of the diagram, leaving space to distribute the nodes that only had one connection around the outside. In that
way, the nodes with only dyadic connections would actually take up the most physical space in the diagram and their single edse would be visually very clear, rather than crossing over lots of o her connections.

\section{Outcome}

From an instructor perspective, one of the best things about this particular exercise was its iterative nature. All three student groups began with the assumption that the lliad network was not real and therefore would not meet the qualifications of their assigned network feature.As they built draft versions of their network out from a starting about how the lliad network functioned began to change. I hoped the process of discussion and network creation would emphasize revision as part of the historical argumentation process, rather than supporting the idea that history arguments are created perfect from hin air the first time. This exceeded my expectations.

Students working in the assortative group [Figure 17] used a combination of dialogue and the familial and adversarial relationships that are documented in the books of the lliad they read. This set of information was fairly easy to collect and document, and as such, they came to a fairly quick conclusion: the lliad has clear clusters of similar people who are highly connected to each other. While the group decided fairly quickly on an argument, they took some time to discuss representational strategies as a consequence of their strong conviction that clusters were an important part of the lliad's social network. Ultimately, they used a combination of color, space and size to create categorized hub-and-spoke shapes designed to emphasize the clusters they saw in the lliad.

Figure 17

$$
\text { ASSCRTAIVE ? }
$$

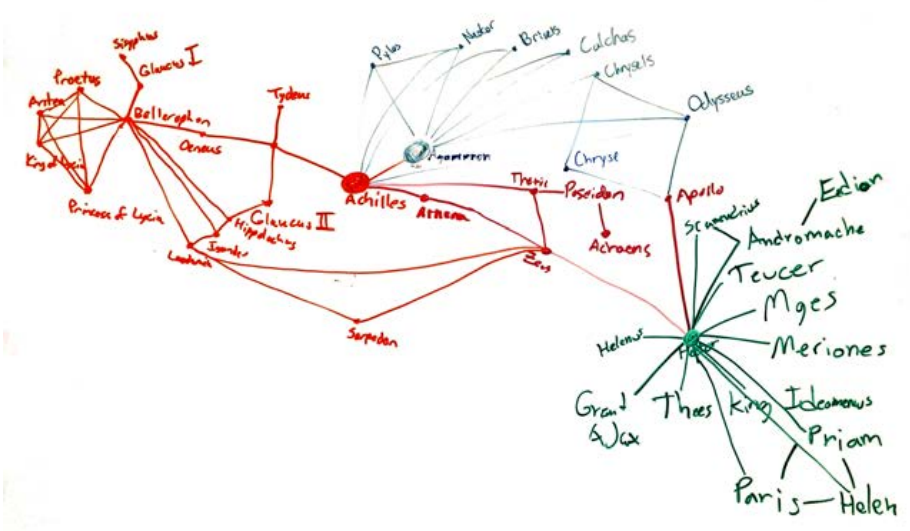

Students working on the balanced network [Figure 18] had the most difficuly formulating an argument, in part because they chose rightly to base their network shape not on co-occurrenceare two characters related or friendly generally - but on whether two characters have a dialogue, and if so, how often. This particular approach generated a series of questions about what constituted overherd and a discussion that the easly-destructible group banced group decided that descriptions of conversations, and the just quoted dialogue, counted, and that there were enough of those a his balance by creating a highly clustered visual diagram colorcoded by relationship group and divided into two to demonstrate where the ic relationships were most prevalent.

Like the students in the assortative group, students in the easily-destructible group [Figure 17] settled on an argument, and an argumentation strategy fairly quickly. They decided the lliad was mostly easily destructible, but they took a very different visual argumentative strategy.They emphasized edge weight, or frequency of connection between two nodes, by drawing thinner or thicker lines 
to demonstrate that Hector, Priam, Achilles and Agamemnon held the mortal world together, with Zeus acting as an intermediary between the mortal world and the gods.

Each of the networks is impressive in its own way, and the students in each group were thoughtful in visual expression of their argument The real value, however, was that the students were able to tie these the lliad, despite the fact that they had only read 3 of the works' 2 total books. The discussion of Greek destruction drawn from thes networks also led several students to make unsolicited comparisons to the lack of cooperation and disintegration of the Greek world in Herodotus' histories, which we read earlier in the semester. One student noted that without the idea of a "real" social network, it fiction and a work ostensibly of history.

Figure 18

BALANCED?

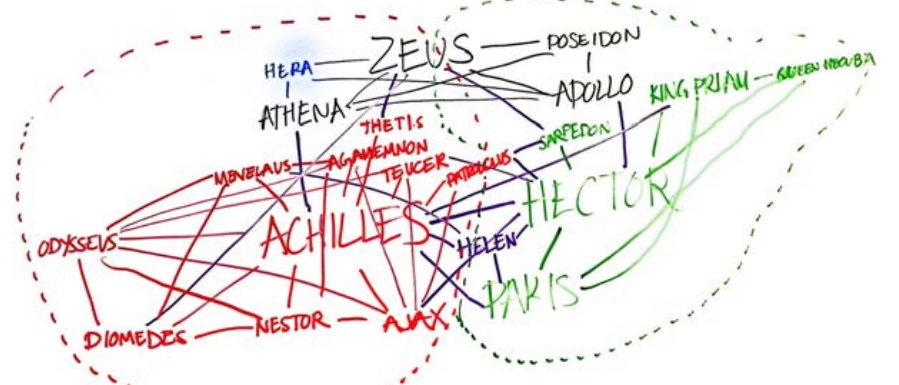

Figure 19

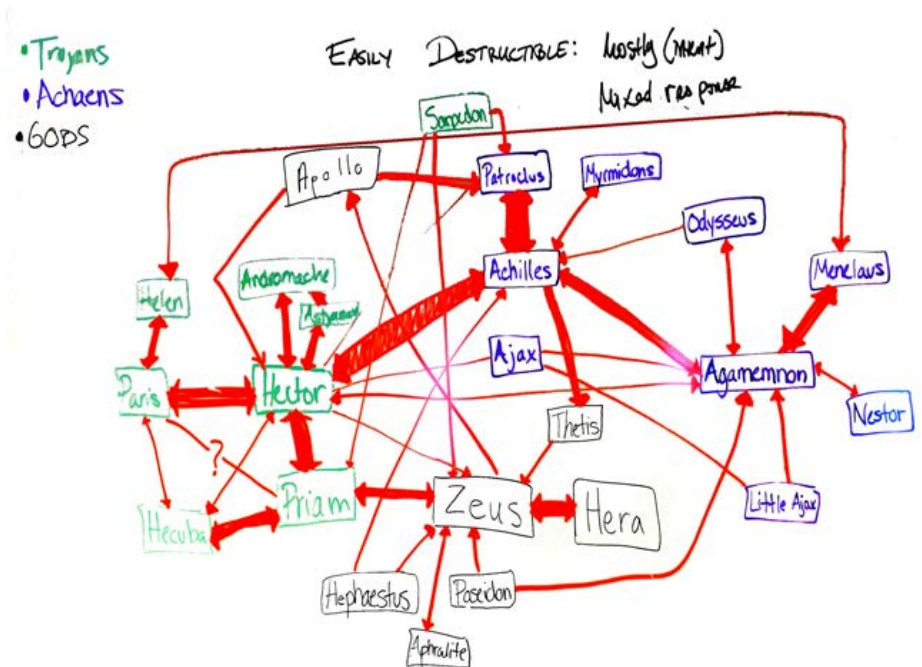

https://doi.orge/10.20429/ijsotl.2017.110107

\section{CONCLUSION}

ination of activity that began this study addresses some of the general concerns historians have as they seek to move students from memorization of facts to use of evidence, context perspective, and corroboration in a historical argument. Each of the thre digital-methodology activities begins with a focus on the object of activity and then uses that object to support the careful selection of digital tools as mediating artifacts. These artifacts can shift students perspective from primary sources as things that need to be read to primary sources as mediating artifacts that can be used.The appropriPation of his new perspective is evidence of a larger pattern of studen digital methodology with historical thinking.

At the same time, these three sessions point to the importance of incorporating digital methodology in incremental terms. A single-session activity is less likely to have any long-term negative effects, but instructors will still be able to capitalize on the positive effects of an activity change, making a single session very low-risk instructional1y. In-class variety keeps students active and emphasizes the differen effects of each methodology's mediation. Using multiple methodologies in a single semester allows instructors to scaffold the students' experiance wh drat af maping to the less familiar network an the which can he su session is successful, it is easy to expand the next time an instructor uses the methodology by comparison, a longer multiple-session pla is harder to condense down into a single session.

Finally, activity theory provides clear solutions to the structural limitations of institutional and personal technology access. Several studies suggest that technology integration into classroom instruction has been slow for a variety of reasons (Li, Worch, Zhou, \& Aguiton, 2015 ), the most notable of which is a lack of institutional technology support. If the mediating artifacts cannot be technology because it is simply not present, but technology as a mediating artifact presents the best tool for a particular learning outcome, then adapting the methodology behind the technology to analog tools like blackboards can help bridge that gap.

Activity theory analysis also points to several advantages in using analog technology to teach digital methodology: first, because there is less to learn from a software perspective (fewer mediating artifacts), the object is easier to achieve. It also has the added benefit of stripping away the speed of a computer and emphasizing the mediation angle of a digital tool: because these activities push students to takeand therefore explicitly grapple with-a new perspective, students can more easily understand how the results of something like tex input to product (rather than simply using a technology and not ta ing a critical stance toward the product and perspective it provides). There are, of course, disadvantages. Computer-mediated activies are faster, provided the learning curve of the software is low).Additionally computer mediation can strip out human confirmation bias, insofar as that is possible. If too much time passes between a student's initial contact with the theory alone and their re-use of the theory combined with a fully digital toolkit, they may need to be reacquainted with both. This limitation weakens some of the advantages of using analog technology in service of learning digital methodology. Still, an activity theory analysis of digital methodology in support of humanities context-making and perspective-taking suggests that, provided digital methodology explicitly supports a history learning outcome, the advantages far outweigh the disadvantages.

While each of the three cases here have some differences, activity theory suggests some overarching guiding principles that make determining the activity's rules, explicit community, and division of labor a more manageable task

First, one of the tricks of systematically using the activity triangle is to prioritize one element in an activity. In these examples, I prioritized bridging the gap between a student's object of activity and professional historian's object in a historical inquiry. This focus offered a more straightforward view of how the digital tools and conceptual tools in the activity might interact to more readily align studen learning objectives with instructor learning objectives, or a barrie to understanding or a tool (or lack thereof) that supports a learning objective, prioritizing a single element in the activity triangle allows

To that end, instructors should explicitly discuss the digital tools as practical elements of a connected world. This can help align student learning objectives with instructor learning objectives. There are two ways to accomplish this. the object of the lesson should have a component that makes use of digital tools students are likely to en-

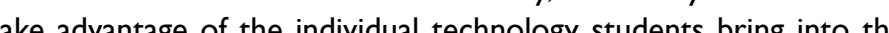
take advantage of the individual technology students bring into the goals bridge the gap between the role of digital technology in the students' everyday life, the importance of using those tools cirically and the ways digital tools align and combine with analog tools and huma cognition. These explicitly position the historical learning objective in service of real-world tasks the student may repeat multiple times outside the walls of the classroom and make it more likely that students will appropriate the critical processes being taught.

Finally, instructors should include advance reading assignments, along with parameters and instructions for the preparatory reading as part of the activity triangle. Students who are directed to simply read will take different elements away from a source than students who are directed to read and take notes about recurring themes, places, names, or other elements. Reading prompts for the sources assigned in advance of these classroom activities should therefore take advantage of the students' existing close-reading skills but should also direct their preparatory reading in a way that supports the affordances of the digital methodology being used for that classroom activity. While the study here is presented in mostly anecdotal terms, with student artifacts providing some context, these initial ideas are quite promising. The lesson plans here allow students to engage a growing field of research without worries about the digital divide, Whout significant time investment on the part of instructors whose does, and by using a systemic approch to acivis phaning the does, and by using a systematic approach to activy planning tha

\section{REFERENCES}

Adler-Kassner, L., Majewski, J., \& Koshnick, D. (2012). The value of troublesome knowledge: Transfer and threshold concepts in writing and history. Composition Forum, 26 (Fall 2012).

Blin, F., \& Munro, M. (2008).Why hasn't technology disrupted academics' teaching practices? Understanding resistance to change through the lens of activity theory. Computers \& Education, 50(2), 475-490. doi:http://dx.doi.org//0.1016/j.compedu.2007.09.017

Cuban, Larry. (1986). Teachers and machines. Teachers College Press. Danish, J. A. (2013). Designing for technology enhanced activity to support learning. The Journal of Emerging Learning Design(I). age: Trinity College (CT) W. (Eds.). (2013). Writing history in the digital WritingHistory.trincoll.edu; University of Michigan Press.

Engeström, Y. (1987). Learning by expanding: an activity-theoretical Op.

Engeström, Y. (1991). Non scolae sed vitae discimus: Toward overcoming the encapsulation of school learning. Learning and Interaction, I, 243-259.

flavell, J. H. (1979). Metacognition and cognitive monitoring: A new area of cognitive-developmental inquiry. American psychologis, $34(10), 906$

Gastner, M. T., Shalizi, C. R., \& Newman, M. E. J. (2005). Maps and cartograms of the 2004 US Presidential Election results. Advances in Complex Systems, 08(01), 117-123. doi:10.1142

Ceeno, J. G. (2006). Learning in Activity. In R. K. Sawyer (Ed.), The Cambridge handbook of the learning sciences (pp. 79-96). New York

Cambride Univ Press.

Pepkow, L. (2004). Learning to use evidence the study of history. New Directions for Teaching and Learning

. The Rare and Excellent History of Saladin Mahasin al-Yusufiyya (D. S. Richards, Trans. D. S. Richards Ed.): Routledge.

Melly. M. (2013). Teaching history in the digital age: University of Michigan Press.

L., Worch, E., Zhou, Y., \& Aguiton, R. (2015). How and why digital generation teachers use technology in the classroom: An for the Scholarship of Teaching and Learning, 9(2).

(2) . A Web 2.0 Class. Students Learn 21 st Century Skills, Collaboration, and Digital Citizenship. Edutopia. Retrieved from http://www.edutopia.org//log/web-20-2I st-century-skillscollaboration-digital-citizenship

Middendorf, J., Diaz,A., Pace, D., \& Shopkow, L. (2007). Making thinking explicit: A history department decodes its discipline. Paper presented at the National Teaching and Learning Forum.

"gan, E.J. (2013).Virtual worlds: Integrating "Second Life" into the history classroom. The History Teacher, 46(4), 547-559.

di, B.A., \& O'Day,V. L. (1999). Information ecologies: Using technology with heart. Cambridge, MA:MIT Press.

Resure (2012). Maps of the 2012 US Presidential Election mersonal umich.edu/ mejn/

D. (2004).

. The amateur in the operating room: History and the scholarship of teaching and learning. The American Historica Review, 109(4) II 17I-1192 doi:10.1086/530753

政, I., \& Kenna, R. (2012). Universal properties of mythologica networks. EPL (Europhysics Letters), 99(2), 28002.

Robison, W. B. (2013). Stimulation, not simulation: An alternate approacs 
the Classroom. The New Yorker.

Roth, W.-M. (2004). INTRODUCTION: "Activity Theory and Education:An Introduction". Mind, Culture, and Activity, I I (I), I-8. doi:I0.1207/s|5327884mcal|0I_I

Russell, D. R. (1997). Writing and genre in higher education and workplaces: A review of studies that use cultural--historical activity theory. Mind, Culture, and Activity, 4(4), 224-237. doi: I0.1207/s I5327884mca0404_2

Russell, D. R. (2013). Activity theory and its implications for writing instruction. In J. Petraglia (Ed.), Reconceiving Writing, Rethinking Writing Instruction (pp. 5I-78): Routledge.

Sadler, D. R. (1998). Formative Assessment: revisiting the territory. Assessment in Education: Principles, Policy \& Practice, 5(I), 77-84. doi:10.1080/0969595980050104

Seefeldt, D., and Thomas, W.G. (2009) What Is Digital History? Perspectives 47 (5). Retrieved from https://www.historians.org/ publications-and-directories/perspectives-on-history/may-2009/ intersections-history-and-new-media/what-is-digital-history

Shopkow, L., Díaz, A., Middendorf, J., \& Pace, D. (20I2). The History Learning Project "decodes" a discipline: The union of teaching and epistemology. In K. McKinney \& M. T. Huber (Eds.), The Scholarship of Teaching and Learning In and Across the Disciplines (pp. 93-I I3). Bloomington, IN: Indiana University Press.

von Schlichten, D. (January 2I, 2015). Students Are Welcome to Shop Online During My Lectures. The Chronicle of Higher Education. Retrieved from http://www.chronicle.com/blogs/ conversation/2015/01/21/students-are-welcome-to-shop-onlineduring-my-lectures/

Vygotsky, L. S. (1978). Mind in society: the development of higher psychological processes. Cambridge: Harvard University Press.

Wilson, N.S. \& Bai, H. Metacognition Learning (2010) 5: 269. doi:I0.1007/s | |409-010-9062-4.

Wineburg, S. (2001). Historical thinking and other unnatural acts: Charting the future of teaching the past. Temple University Press.

Yorke, M. (2003). Formative assessment in higher education: Moves towards theory and the enhancement of pedagogic practice. Higher Education, 45(4), 477-50I. doi:I0.1023/A:10239670264I3 